\title{
Polarization Study on the Inhibition of Iron Corrosion by means of Phenylalkyl Amines in Acid Solution
}

\author{
Kunitsugu ARAMAKI*
}

\begin{abstract}
The inhibition effect of $\omega$-phenylalkyl amines and $\omega$-cyclohexylalkyl amines on the corrosion of pure iron was studied in a $6.1 \mathrm{M} \mathrm{HCl}$ solution by polarization measurement. The inhibition efficiency of these amines was determined on the basis of general adsorption behavior, using molecular coverage areas, the $\mathrm{pK}_{\mathrm{a}}$ values, and the polar and steric substituent constants. Most of the amines inhibited the cathodic and anodic processes of the corrosion reaction. The efficiency of $\omega$-phenylalkyl amines was lower than that of the corresponding $\omega$-cyclohexylalkyl amines; the cations of the former are adsorbed on the cathodic surface in parallel orientation mode by electrostatic attraction and by interaction between the metal and the phenyl group. The interaction between the metal and molecules of phenylalkyl amine in its resonance structure plays an important role in its adsorption on the anodic surface. The anodic inhibition efficiency of the phenylalkyl amines can be expressed in terms of polar and steric substituent constants and in terms of a factor related to the effect of their resonance structures on adsorption.
\end{abstract}

\section{Introduction}

A number of investigations have been reported on the inhibition of iron corrosion by means of aniline derivatives in acid solutions. According to the concept of general adsorption, amine inhibitors are adsorbed on the metal surface by the formation of a coordination bond between the metal and the nitrogen atom and by electrostatic attraction between the cathodic surface and ammonium cations which form in the acid solutions ${ }^{1,2)}$. Furthermore, flat adsorption of anilines on the surface can occur by $\pi$-electron bonding between the metal and the phenyl group $^{3)}$. Therefore, the inhibition efficiency of aniline derivatives for iron corrosion in acid solutions is related not only to the electron density of the nitrogen atoms but also to the $\pi$-electron density of the phenyl group ${ }^{4}$. The present work was undertaken to elucidate the effect of the phenyl group on the corrosion inhibition efficiency of phenylalkyl amines. The efficiency of $\omega$-phenylalkyl amines for iron corrosion in $6.1 \mathrm{M} \mathrm{HCl}$ was obtained by polarization measurements and discussed with respect to the $\mathrm{pK}_{\mathrm{a}}$ value, the polar and steric subst $\mathrm{j}$ -

* Faculty of Engineering, Keio University at Hiyoshi (4-1-1 Hiyoshi, Kohoku-ku, Yokohama) tuent constants, and the molecular size of these amines.

\subsection{Inhibitors}

\section{Experimental}

The inhibitors used were $\omega$-phenylalkyl amines $\left(\mathrm{C}_{6} \mathrm{H}_{5}\left(\mathrm{CH}_{2}\right)_{\mathbf{n}} \mathrm{NH}_{2}\right.$, where $\left.n=0-3\right)$, and $\omega$-cyclohexylalkyl amines $\left(\mathrm{C}_{6} \mathrm{H}_{11}\left(\mathrm{CH}_{2}\right)_{n} \mathrm{NH}_{2}\right.$, where $n=0-3)$. The former were obtained as high-grade commercial reagents and purified by recrystallization of their salts with hydrochloric acid. The latter series, with the exception of cyclohexylamine, were synthesized by the catalytic hydrogenation of the corresponding $\omega$-phenylalkyl amine and all were purified by fractional distillation before use.

\subsection{Polarization measurements}

Corrosion rates of a $99.89 \%$ iron electrode*1 (Mallinckrodt analytical reagent grade) were determined at $30 \pm 0.1^{\circ} \mathrm{C}$ in inhibited and uninhibited $6.1 \mathrm{M} \mathrm{HCl}$ solutions by galvanostatic polarization. The details of these measurements have previously been given ${ }^{5}$ ).

2.3 Determinations of molecular coverage area and basicity

*1 C, $0.03 \% ; \mathrm{Mn}, 0.04 \% ; \mathrm{P}, 0.002 \% ; \mathrm{Si}, 0.001 \% ; \mathrm{S}$, $0.02 \%$ 
The coverage area of each inhibitor molecule was determined by arranging the StuartBriegleb molecular models on a plane in the position corresponding to the appropriate confor7 mation and orientation mode of the molecule adsorbed on the metal surface. Two kinds of adsorption were assumed in determining area-coulombic adsorption of the ammonium cation, and coordination adsorption of the unprotonated amine. For both the adsorbed cation and amine, two orientation modes were assumedin the first, the molecules are adsorbed on the surface without any interaction between the metal and the phenyl group; in the second, the phenylalkyl amine inhibitor is adsorbed by the formation of a metal-nitrogen bond under the influence of $\pi$-electron interaction between the metal and the phenyl group. In the second orientation mode, the inhibitor molecules are adsorbed in parallel with the surface. Determi. nation of the molecular coverage area has been described in greater detail elsewhere ${ }^{6}$.

The $\mathrm{pK}_{\mathrm{a}}$ values for some of the inhibitors were determined by titration with $\mathrm{HClO}_{4}$ in water at $25^{\circ} \mathrm{C}$.

\section{Results}

The corrosion current $i_{\text {corr }}$ and the corrosion

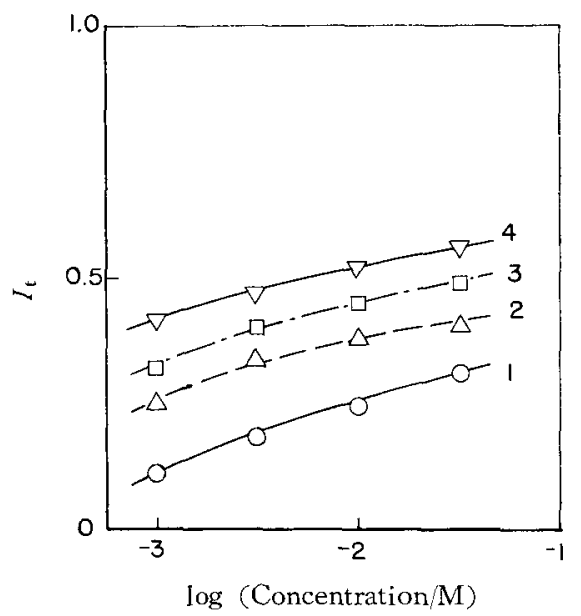

(a)

Fig. 1 Total inhibition efficiency $I_{\mathrm{t}}$

a) for $\omega$-phenylalkyl amines: 1 , aniline; 2, benzylamine; 3 , 2-phenylethylamine; 4, 3-phenylpropylamine

b) for $\omega$-cyclohexylalkyl amines: 5 , cyclohexylamine $($ purified by recrystallization of its chloride); 6, cyclohexylmethylamine; 7, 2-cyclohexylethylamine; 8,3 -cyclohexylpropylamine potential $E_{\text {corr }}$ were obtained by intersection of well-defined cathodic and anodic Tafel lines. The polarization curves showed that most of the amines inhibited both the cathodic and the anodic processes of the corrosion reactions. $E_{\text {corr }}$ and the cathodic and anodic Tafel slopes $b_{\mathrm{c}}$ and $b_{\mathrm{a}}$ at an inhibitor concentration of 0.01 $\mathrm{M}$ are tabulated in Table 1 . The $E_{\text {corr }}$ values for the inhibited electrodes shifted toward the less noble potential by no more than $30 \mathrm{mV}$ from those for the uninhibited electrode $E_{\text {corr }}^{o}$. There was no significant spread of values for each of the Tafel slopes.

Figure 1 shows the total inhibition efficiency Table 1 Polarization data at an inhibitor concentration of $0.01 \mathrm{M}$

\begin{tabular}{l|l|r|r|r}
\hline No. & \multicolumn{1}{|c|}{ Inhibitor } & $\begin{array}{c}E_{\text {corr }} \\
(\mathrm{mV} v s .\end{array}$ & $\begin{array}{c}b_{\mathrm{c}} \\
\mathrm{SCE})\end{array}$ & $\begin{array}{c}\bar{b}_{\mathrm{a}} \\
(\mathrm{mV})\end{array}$ \\
\hline 0 & none & -467 & 154 & 110 \\
1 & aniline & -474 & 155 & 112 \\
2 & benzylamine & -478 & 153 & 110 \\
3 & 2 -phenylethylamine & -480 & 155 & 110 \\
4 & 3 -phenylpropylamine & -484 & 153 & 112 \\
5 & cyclohexylamine & -479 & 156 & 111 \\
6 & cyclohexylmethylamine & -488 & 154 & 111 \\
7 & 2 -cyclohexylethylamine & -484 & 153 & 112 \\
8 & 3 -cyclohexylpropylamine & -472 & 158 & 116 \\
\hline
\end{tabular}

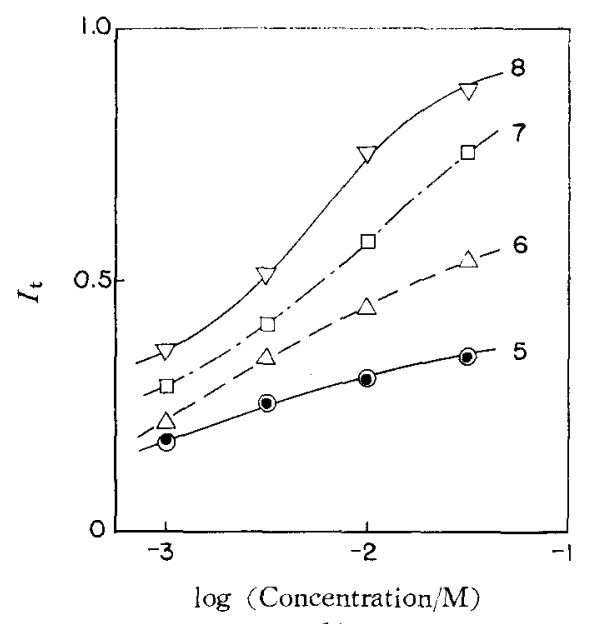

(b) 
$I_{\mathrm{t}}$ given by

$$
I_{\mathrm{t}}=1-i_{\mathrm{corr}} / i_{\text {corr }}^{\circ}
$$

where $i_{\text {corr }}$ and $i_{\text {corr }}^{\circ}$ are the corrosion currents for the inhibited and uninhibited electrodes, respectively. For both series of amines, $I_{t}$ increased with an increase in the carbon number of the alkyl group. The phenylalkyl amines were found to be less effective inhibitors than the corresponding cyclohexyl compounds.

It has been reported that aromatic compounds purified only by distillation are better inhibitors than the corresponding compounds subjected to extensive purification ${ }^{7}$. For this reason, recrystallized $\omega$-phenylalkyl ammonium chlorides were used in this experiment. No recrystallization of the chlorides was employed in the purification of the $\omega$-cyclohexylalkyl amines since, as shown in Fig. $1 \mathrm{~b}$, the $I_{\mathrm{t}}$ values of samples of cyclohexylamine purified by distillation were in good agreement with those purified by chloride recrystallization.

\section{Discussion}

If the values of $b_{c}$ and $b_{\mathrm{a}}$ are constant, the inhibition effect can be given in terms of cathodic and anodic inhibition efficiencies $I_{\mathrm{c}}$ and $I_{\mathrm{a}}$ as :

$$
\begin{aligned}
& I_{\mathrm{c}}=1-i_{\mathrm{c}} / i^{\mathrm{o}}{ }^{\mathrm{Corr}} \\
& I_{\mathrm{a}}=1-i_{\mathrm{a}} i^{\circ}{ }^{\circ}{ }^{\circ}{ }^{2} \mathrm{r}
\end{aligned}
$$

where $i_{\mathrm{c}}$ and $i_{\mathrm{a}}$ are the current densities obtained by extrapolating the cathodic and anodic Tafel lines, respectively, at $E_{\text {corr }}^{o}$

The inhibition of the cathodic process by amine inhibitors was assumed to depend on the coulombic adsorption of ammonium cations on the cathode, as has been shown in previous papers $^{8), 9}$, The cathodic inhibition efficiency can then be expressed by

$$
I_{\mathrm{c}} / \mathrm{A}^{+}=\text {const. } \frac{K_{\mathrm{ads}}}{K_{\mathrm{a}}}\left[\mathrm{RNH}_{\mathrm{a}}\right]\left[\mathrm{H}^{+}\right][\mathrm{M}]
$$

where $K_{\mathrm{ads}}$ and $K_{\mathrm{a}}$ are equilibrium constants for the adsorption and dissociation of the ammonium cation, respectively, and $A^{+}$is the molecular coverage area of the cation. A $0.01 \mathrm{M}$ cyclohexylamine solution was adopted as the referent for determining the values of $I_{\mathrm{c}}$ at a constant concentration of free amines. The concentration of the other amines $\left(C^{\prime}\right)$ at which free amine concentration equals that of the referent was calculated by

$$
\mathrm{C}^{\prime}=0.01 K_{\mathrm{a}} / K_{\mathrm{a}}^{\prime}
$$

where $K_{\mathrm{a}}$ and $K_{\mathrm{a}}^{\prime}$ are the dissociation constant for the ammomium cations of cyclohexylamin and of any other amine, respectively. Th cathodic inhibition efficiency at $C^{\prime}\left(I^{\prime}{ }_{c}\right)$ wa obtained by interpolation of the curve of $I$ versus inhibitor concentration $(C)$, but $I^{\prime}{ }_{c}$ fo aniline was not obtainable because $K^{\prime}$ is ex tremely large.

Since $[\mathrm{M}]$ and $\left[\mathrm{H}^{+}\right]$in eq. (4) are constant $I^{\prime}{ }_{\mathrm{c}} / A^{+}$should be proportional to $1 / K_{\mathrm{a}}$ if $K_{\mathrm{ad}}$ is unchanged.

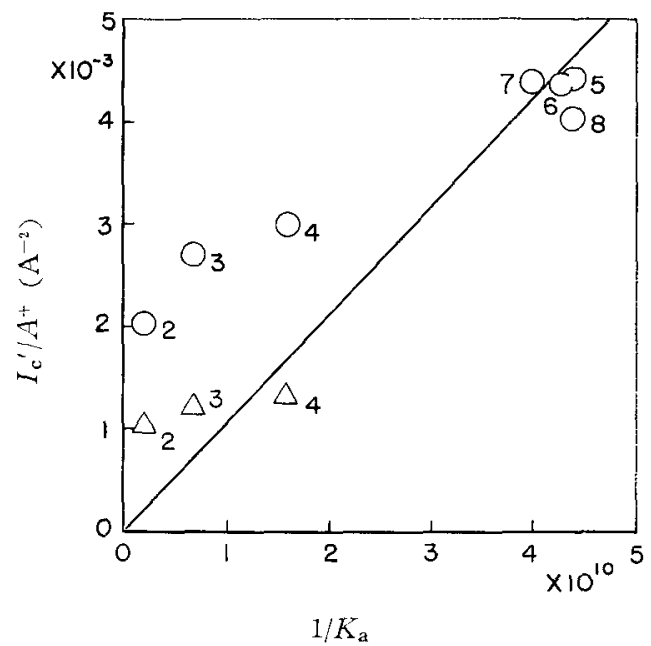

Fig. 2 Relationship between $I_{c}^{\prime} / A^{+}$and

$$
\begin{aligned}
& 1 / K_{\mathrm{a}} \\
& \bigcirc: A^{+}=A^{+}, \triangle: A^{+}=A^{+}{ }_{2}
\end{aligned}
$$

A plot of the circles in Fig. 2 indicates this correlation based on the molecular coverage area of the cation in the first orientation mode $\left(A_{1}^{+}\right)$(numbers refer to the jnhibitors in Table 1). The diagonal line in Fig. 2 shows this correlation, which has been reported for a series of alkyl amines in the previous paper ${ }^{8}$. The plots for $\omega$-cyclohexylalkyl amines were located near the line. On the other hand, the values of $I_{\mathrm{c}}{ }^{\prime} / A_{1}{ }^{+}$for $\omega$-phenylalkyl amines were higher than those for the alkyl amines. This indicates that the phenyl group causes the $I_{\mathrm{c}}$ of aljphatic or alicyclic amines to increase.

Phenylalkyl ammonium ions may be adsorbed on the cathodic surface by means of ionic at traction and by interaction between the meta and the phenyl group. 
The value of $I_{\mathrm{c}}{ }^{\prime} / \mathrm{A}_{2}{ }^{+}$(i.e. coverage are in the second mode) for each of the $\omega$-phenylalkyl amines is plotted as a triangle in Fig. 2. The second mode plots for benzylamine and 2phenylethylamine were also above the diagonal line. This result shows that the phenyl group increases $K_{\mathrm{ads}}$ in eq. (4). The amounts by which the values of $I_{\mathrm{c}} / A_{2}{ }^{+}$for the phenyl alkyl amines deviated from the values for the alkyl amines shown by the diagonal line in Fig. $2\left(\Delta I_{c}{ }^{\prime} / A_{2}{ }^{+}\right)$were measured, and plotted

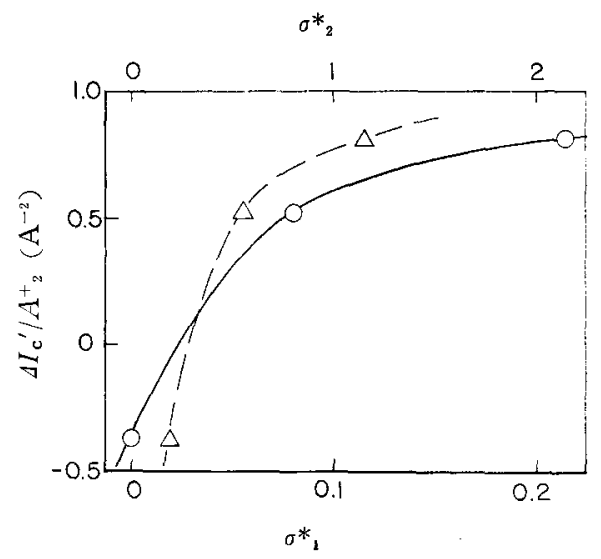

Fig. 3 Correlation of $I_{\mathfrak{c}}{ }^{\prime} / A_{2}{ }^{+}$to $\sigma^{*}{ }_{1}(O)$ and $\sigma_{2}^{*}(\triangle)$

in Fig. 3 against $\sigma^{*}$, the polar substituent constant of the $\omega$-phenylalkyl group attached to the nitrogen atoms. The value of $\Delta I_{\mathrm{c}}{ }^{\prime} / \mathrm{A}_{2}{ }^{+}$ increased with increases in $\sigma^{*}{ }_{1}$ and this is similar to the result obtained for olefinic

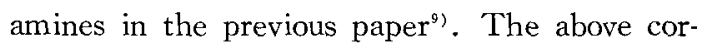
relation indicates that cathodic inhibition efficiency increases with a decrease in electron density of the nitrogen atoms. The increase in the $I_{\mathrm{c}}$ of the phenylalkyl amines cannot, therefore, be attributed to coordination adsorption of the unprotonated amine, but may in part be caused by the reinforced coulombic adsorption of the phenylalkyl ammonium cation on the cathode by an enhanced positive charge due to the inductive effect of the phenyl group ${ }^{10}$.

In order to investigate the interaction between the metal and the phenyl group of the cation, $\Delta I^{\prime}{ }_{\mathrm{c}} / A_{2}{ }^{+}$was also plotted against $\sigma^{*}{ }_{2}$, the polar substituent constant of substituents $\left(-\mathrm{CH}_{2}\right)_{\mathrm{n}} \mathrm{NH}_{3}{ }^{+}$ $(n=1-3)$ (see Fig. 3). This correlation showed that $\Delta I^{\prime}{ }_{\mathrm{c}} / A_{2}{ }^{+}$increased with decreasing $\pi$-electron density of the phenyl group. It can be supposed from this correlation that the increase in $I_{\mathrm{c}}$ for the phenylalkyl amines is caused not by the coordination of $\pi$-electrons on the phenyl group to the metal orbitals, but by other interactions such as a back-donation of metal electrons to vacant orbitals in the phenyl group.

If the activation energy of the corrosion process is not changed by the adsorption of inhibitors, $I_{\mathrm{a}}$ is expressed approximately by the Hammett-like equation

$$
\log \left(I_{\mathrm{a}} A_{\mathrm{o}} / I_{\mathrm{a} o} A\right)=\rho^{*} \Sigma \sigma^{*}+\delta E_{\mathrm{s}}+\alpha \quad(6)
$$

where zero subscripts refer to a reference inhibitor, $\mathrm{A}$ is the molecular coverage area of free amines, $\Sigma \sigma^{*}$ and $E_{\mathrm{s}}$ denote the polar and steric substituent constants, respectively, and $\rho^{*}, \delta$, and $\alpha$ are constants ${ }^{11}$. The term $\delta E_{\mathrm{s}}$ is a measure of the steric requirements for the adsorption of inhibitors. Although the values of $E_{\mathrm{s}}$ for some of the substituents in the amines used were unknown, $\delta E_{\mathrm{s}}$ was neglected in this discussion because the constant $\delta$ was taken to be negligible for primary amines ${ }^{12}$. The reference inhibitor was cyclohexylamine.

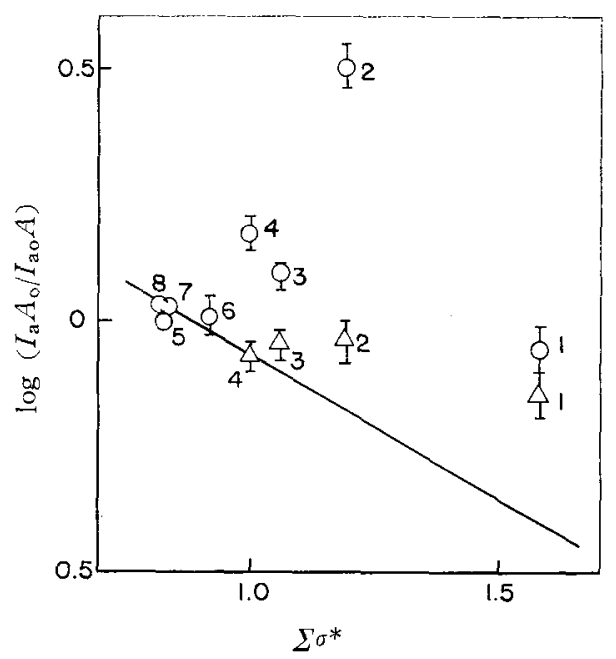

Fig. 4 Relationship between $\log \left(I_{\mathbf{a}} A_{\mathbf{o}} /\right.$

$$
\begin{aligned}
& \left.I_{\mathrm{ao}} A\right) \text { and } \Sigma \sigma^{*} \\
& \quad O: A=A_{1}, \triangle: A=A_{2}
\end{aligned}
$$

The plot of circles in Fig. 4 shows the relationship given by eq. (6), based on the coverage area of the adsorbed free amine in the first orientation mode $\left(A_{1}\right)$. Each circle shows the average value and the error limits of the values of $\log \left(I_{\mathrm{a}} A_{1, o} / I_{\mathrm{a} o} A_{1}\right)$ at the four inhibitor concentrations adopted in this experiment (num- 
bers refer to the inhibitors in Table 1 ). A straight line having a slope $\rho^{*}=-0.584$ (the value obtained for alkyl amines ${ }^{13}$ ) was drawn so as to intersect the circles for the cyclohexylalkyl amines. Thus, if this line shows the relationship in eq. (6) for the cyclohexylalkyl amines, the values of $\log \left(I_{\mathrm{a}} A_{1}, \mathrm{o}_{\mathrm{ad}} A_{1}\right)$ for the phenylalkyl amines will be larger than those for the amines previously studied. On the assumption that the phenylalkyl amines are adsorbed parallel to the surface, the molecular coverage area in the second orientation mode $\left(A_{2}\right)$ was substituted in eq. (6), and $\log \left(I_{\mathrm{a}} A_{2, \mathrm{o}}\right)$ $I_{\mathrm{ao}} A_{2}$ ) was also plotted against $\Sigma \sigma^{*}$ (triangles in Fig. 4). The logarithmic values for most of the phenylalkyl amines were larger than those for the cyclohexylalkyl amines. This increment of $I_{\mathrm{a}}$ can be attributed to the increased adsorbability of $\omega$-phenylalkyl amines due to the $\pi$-electron interaction between the metal and the phenyl group.

The difference of amount, by which the values of $\log \left(I_{\mathrm{a}} A_{2, \mathrm{o}} / I_{\mathrm{ao}} A_{2}\right)$ for the phenylalkyl amines deviated from the values for the cyclohexylalkyl amines shown by the diagonal line in Fig. 4, $\left(\psi_{\mathrm{r}}\right)$ was plotted in Fig. 5 against $n$, the number

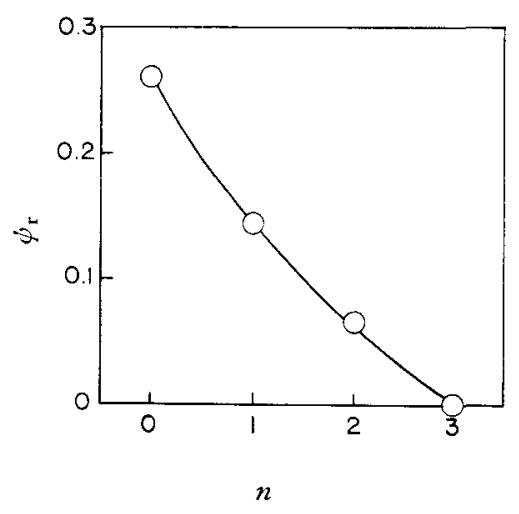

Fig. 5 Correlation of $\phi_{\mathrm{r}}$ to $n$

of methylene groups in the $\omega$-phenylalkyl group $\left(\mathrm{C}_{6} \mathrm{H}_{5}\left(\mathrm{CH}_{2}\right)_{\mathrm{n}}\right)$. This value decreased with an increase in $n$, reaching zero at $n=3$. The electron density of the nitrogen atoms in aniline is relatively low compared with those in the cyclohexylalkyl amines because of the resonance effect of the phenyl group. Therefore, the density of delocalized $\pi$-electrons in the aniline molecule should be high. The $\pi$-electron density tends to decrease with increasing values of $n$ since the resonance effect of the phenyl grour on the electrons of the nitrogen atoms is block. ed by the methylene groups. The tendency toward a decrease in the $\pi$-electron density car be presumed from the $\Sigma a^{*}$ values or from the basicity constants of $\omega$-phenylalkyl amines. The difference $\phi_{\mathrm{r}}$ is thus attributed to reinforced adsorption by virtue of the interaction between the metal and inhibitor molecules using the delocalized $\pi$-electrons of the phenyl alkyl amines.

Equation (6) can be rewritten using $\psi_{\mathrm{r}}$, as $\log \left(I_{\mathrm{a}} A_{\mathrm{o}} / I_{\mathrm{a} o} A\right)=\rho^{*} \Sigma \sigma^{*}+\delta E_{\mathrm{s}}+\psi_{\mathrm{r}}+\alpha$

The reinforced adsorption of allylamine, describ ed in a previous paper ${ }^{14}$, may also be related to this term.

\section{Conlusion}

Most $\omega$-phenylalkyl and $\omega$-cyclohexylalkyl amines inhibited both the cathodic and anodic processes of iron corrosion in a $6.1 \mathrm{M} \mathrm{HCl}$ solution. It was found that the phenylalky] ammonium ions are adsorbed on the cathodic surface in the parallel (second) orientation mode by electrostatic attraction and by the interaction between the metal and the phenyl group. The anodic inhibition efficiency showed that the phenylalkyl amine molecules are adsorbed on the anode in the parallel mode by the formation of coordination bonds between the metal and the nitrogen atoms and also between the metal and the resonating molecules. The anodic inhibition efficiency of $\omega$-phenylalkyl amines was expressed as a Hammtt-like equation in terms of the effect of the resonance structures on the anodic inhibition efficiency $\left(\phi_{\mathrm{r}}\right)$, the value of which decreased with increases in the number of methylene groups in $\omega$-phenylalkylamines, becoming zero for 3-phenylpropylamine.

$<$ E480 $>$ (Received Aug. 30,1976)

\section{References:}

1) H. Kaesche and N. Hackerman, j. Electrochem. Soc. 105, 191 (1958).

2) J. Vosta, J. Eliasek and P. Knizek, Corrosion 32, 183 (1976).

3) E. Blomgren and J. O'M. Bockris, J. Phys. Chem. 63, 1475 (1959).

4) A.I. Altsybeeva, S.Z. Levin and A.P. Dorokov, "Proceedings 3 rd European Symposium on Corro- 
sion Inhibitors", p. 501 (1971). Universitá Degli Studi di Ferrara, Ferrara.

5) K. Aramaki and N. Hackerman, J. Electrochem. Soc. 115, 1007 (1968).

6) K. Aramaki, This Journal 42, 75 (1974).

7) R.C. Ayers, Jr. and N. Hackerman, J. Electrochem. Soc. 110, 507 (1963).

8) K. Aramaki, This Joumal 42, 566 (1974).
9) K. Aramaki, ibid. 44, 771 (1976).

10) V.P. Grigoryev and O.A. Osipov, "Proceedings 3 rd International Congress on Metallic Corrosion" Vol. 2, p. 48 (1966), Swets-Zeitlinger, Amsterdam.

11) K. Aramaki, This Journal 41, 321 (1973).

12) K. Armaki, Boshoku Gijutsu 26, 297 (1977).

13) K. Aramaki, This Joumal 41, 875 (1973).

14) K. Aramaki, ibid. 43, 696 (1975).

\section{$E \times$ e $\mathbf{g} \mathbf{y}$}

近頃，エネルギーの有効利用との関連で，エクセルギーといらことばをよく耳にする，エクセルギーとは，熱 力学の用語であって，最小作用の原理，最大仕事の原理とまったく同様の物理的意味をもっており，

$$
\varepsilon=\left(\mathrm{H}-\mathrm{H}_{0}\right)-\mathrm{T}_{0}\left(\mathrm{~S}-\mathrm{S}_{0}\right)
$$

によって定義される状態量である.ここで， $\mathrm{H}_{0}, \mathrm{~T}_{0}, \mathrm{~S}_{0}$ はおおのおのの系が与えられた環境（通常 1 気圧， $25^{\circ} \mathrm{C}$ ) と平衡になったときのエンタルピー, 温度, エントロピーである. 最大仕事の原理からわかるように, エクセル ギーは系が与えられた状態より環境と平衡となるまでの間に可逆過程においてなし得る最大の仕事量をあらわし ている、したがってこの過程の間に不可逆過程が含まれていればそれ以下の有效仕事しか系はなし得ない。この 差はしばしばエクセルギー損失と呼ばれる.エクセルギー損失はエントロピー生成によって表わすことができ る.すなわち，上式の微分をとると

$$
d \varepsilon=d \mathrm{H}-\mathrm{T}_{0} d \mathrm{~S}
$$

エントロピー変化をエントロピー流とエントロピー生成に分けて， $d \mathrm{~S}=d_{\mathrm{e}} \mathrm{S}-d_{\mathrm{i}} \mathrm{S}$ と表記すれば，

$$
d \varepsilon=d \mathrm{H}-\mathrm{T}_{0} d_{\mathrm{e}} \mathrm{S}-\mathrm{T}_{0} d_{\mathrm{i}} \mathrm{S}
$$

すなわち，不可逆過程が含まれているとき， $\mathrm{T}_{0} d_{\mathrm{i}} \mathrm{S}$ がエクセルギー損失となる．このエントロピー生成は系が環 境々平衡にない任意の温度におけるものであり，そのためのエクセルギー損失は $\mathrm{T} d_{\mathrm{i}} \mathrm{S}$ ではなく $\mathrm{T}_{0} d_{\mathrm{i}} \mathrm{S}$ と環境 との関連で定義されることに注意していただきたい． 